\title{
Влияние содержания меди на кинетику микроволновой фотопроводимости твердых растворов CIGS
}

\author{
(C) Г.Ф. Новиков ${ }^{1,2}$, Е.В. Рабенок ${ }^{1}$, П.С. Оришина ${ }^{1,2}$, М.В. Гапанович ${ }^{1}$, И.Н. Один ${ }^{2}$ \\ ${ }^{1}$ Институт проблем химической фризики Российской академии наук, \\ 142432 Черноголовка, Россия \\ ${ }^{2}$ Московский государственный университет им. М.В. Ломоносова, \\ 119991 Москва, Россия \\ E-mail: gfnovikov@gmail.com
}

(Получена 8 октября 2018 г. Принята к печати 15 октября 2018 г.)

Исследована кинетика фотоотклика микроволновой фотопроводимости (9ГГц, полостной резонатор $\mathrm{TE}_{101}$-типа) при возбуждении лазерными импульсами света (длина волны 337 нм, длительность 8 нс) в медь-дефицитных твердых растворах со структурой халькопирита $\mathrm{Cu}_{1-x}\left(\mathrm{In}_{0.7} \mathrm{Ga}_{0.3}\right) \mathrm{Se}_{2}, 0<x \leq 0.4$ (CIGS) в широком диапазоне интенсивностей света. При повышении плотности лазерного излучения до уровня $\sim 5 \cdot 10^{14}$ фотон/см${ }^{2}$ за импульс в характере фотоотклика наряду с ранее обнаруженным скин-эффектом проявляется эффект заполнения ловушек, создаваемых вакансиями $V_{\mathrm{Cu}}$ и ассоциатами дефектов $\mathrm{Cu}^{+2} \cdot V_{\mathrm{Cu}}$, концентрация которых увеличивается при уменьшении значения $x$ в формуле для CIGS.

DOI: 10.21883/FTP.2019.03.47282.8994

\section{1. Введение}

Согласно общим представленииям о природе фотовольтаического напряжения, возникающего при освещении двухслойной системы, в которой поглощающий слой - неорганический полупроводник [1], эффективность прямого преобразования света в электричество существенно зависит от диффузионной длины пробега носителей тока $L=(D \tau)^{1 / 2}$ в этом слое (здесь $D$ и $\tau-$ коэффициент диффузии и время жизни носителей тока соответственно). Наглядные представления о степени такой зависимости дают численные расчеты SCAPS [2], позволяющие при наличии необходимых расчетных параметров учесть влияние химического состава и структуры поглощающих слоев на фотовольтаические свойства преобразователей. Ярким примером систем, позволяющих в широких пределах менять химический состав поглощающих слоев, служат четверные соединения меди типа $\mathrm{Cu}(\mathrm{InGa}) \mathrm{Se}_{2}$ (CIGS). В последнее время пленки соединений этого типа хорошо зарекомендовали себя в тонкопленочных солнечных элементах (ТСЭ). Однако, хотя кпд солнечных элементов на основе таких слоев достиг 21.7\% [3], он все же еще далек от теоретического предела $\sim 30 \%$ [4]. Причины такого отставания пока не выяснены, возможно, из-за недостатка необходимых параметров для расчетов и корректировки технологии.

Влияние состава поглощающих слоев на фотовольтаические параметры экспериментально наблюдалось неоднократно. Например, согласно имеющимся литературным данным [5-8], недостаток содержания меди в поглощающем слое благоприятно сказывается на характеристиках ТСЭ. Возможным объяснением данного эффекта может быть результат того, что в стехиометрическом и обедненном составе могут существенно различаться не только концентрации, но и пространственные распределения дефектов, что может влиять на дрейфовые подвижности и времена жизни носителей тока и процессы разделения зарядов.

Цель данной работы состояла в изучении влияния недостатка меди на кинетику гибели фотогенерированных носилей тока и их времена жизни в твердых растворах $\mathrm{Cu}_{1-x}\left(\mathrm{In}_{0.7} \mathrm{Ga}_{0.3}\right) \mathrm{Se}_{2}$. Частично предварительные данные были представлены в [9-11].

\section{2. Экспериментальная часть}

Одним из методов, позволяющих исследовать кинетику гибели фотогенерированных носителей тока, является метод время-разрешенной люминесценции [12,13], основанный на исследовании кинетики затухания спектра излучения. Однако этим методом регистрируются только процессы, протекающие с излучением света, например рекомбинационная люминесценция. Для регистрации процессов гибели свободных носителей тока, идущих без излучения света - захват акцепторами, ловушками, электронно-дырочная рекомбинация, рекомбинация через локализованные состояния, в том числе для случая безызлучательной люминесценции, метод времяразрешенной люминесценции не пригоден. Электрические методы применимы в более общем случае. Одним из таких методов является метод время-разрешенной микроволновой фотопроводимости (FTRMC) [14]. Этот метод позволяет следить за изменением концентрации носителей тока в зоне проводимости. Кроме того, благодаря обычно малому дрейфовому смещению носителей тока под действием электрического поля метод позволяет исследовать как микро-, так и макрообъекты.

В данной работе для исследований применен метод FTRMC в диапазоне частот 9ГГц при комнатной температуре. Временно́е разрешение электрической цепи было $\sim 50$ нс. Для определения времени жизни носи- 

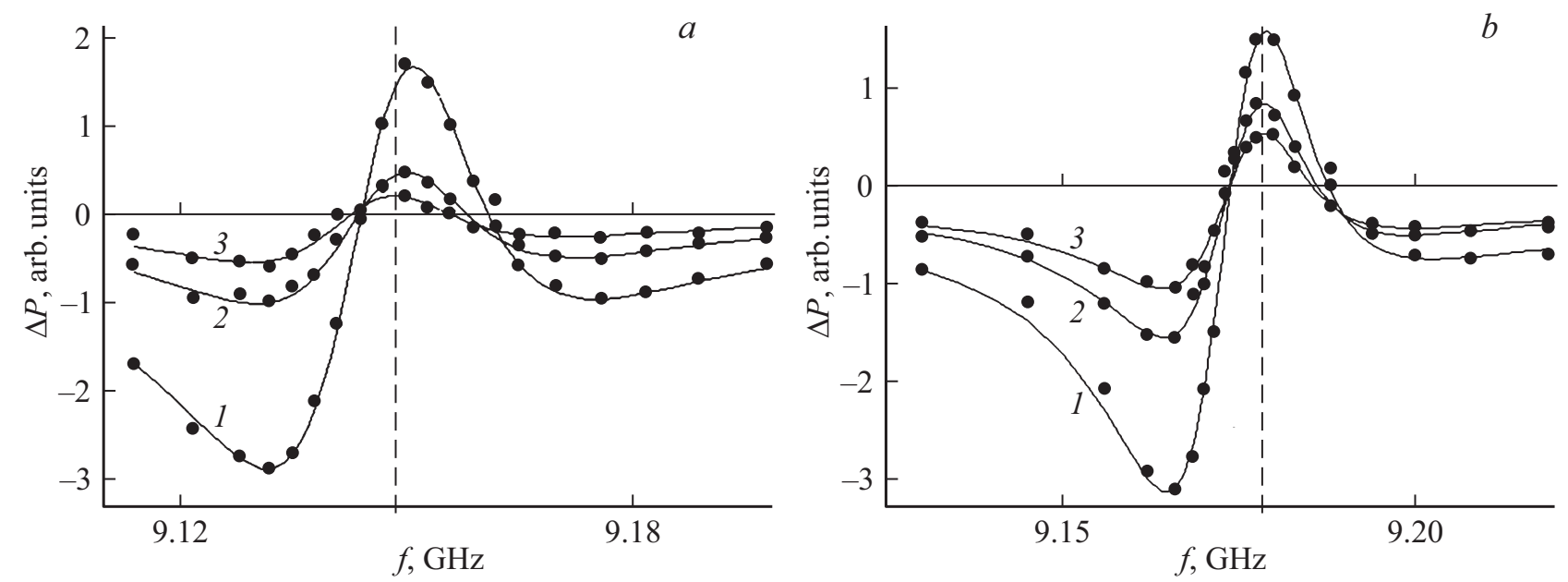

Рис. 1. Экспериментальные зависимости фотоотклика от частоты СВЧ-генератора для некоторых моментов времени в образцах: $a-\mathrm{Cu}\left(\mathrm{In}_{0.7} \mathrm{Ga}_{0.3}\right) \mathrm{Se}_{2}, b-\mathrm{Cu}_{0.6}\left(\operatorname{In}_{0.7} \mathrm{Ga}_{0.3}\right) \mathrm{Se}_{2}: 1-150,2-350,3-550$ нс. Линейной зависимостью показаны результаты аппроксимации. Пунктирной линией на графике показана резонансная частота $f_{0}$.

телей тока применяли методику разделения вкладов в фотоотклик $\Delta P(f, t)$ сдвига резонансной частоты, $\delta f_{0}$, и изменения нагруженной добротности, $\Delta Q$, резонатора. Для этого анализировали зависимости фотоотклика $\Delta P(f, t)$ от частоты СВЧ-генератора $(f)$ в разные моменты времени $(t)[14,15]$. Фотопроводимость возбуждали азотным лазером ЛГИ-505 (длина волны $\lambda=337$ нм, длительность импульса 8 нс). Максимальная плотность светового потока, падающего на образец за

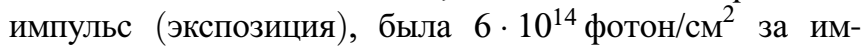
пульс. Интенсивность света в экспериментах изменяли светофильтрами.

Синтез и РФА данные поликристаллических образцов $\mathrm{Cu}_{1-x}\left(\operatorname{In}_{0.7} \mathrm{Ga}_{0.3}\right) \mathrm{Se}_{2}(0<x<0.35)$ представлены в работах [9,10]. Исследования катодолюминесценции $[9,10,16]$ показали, что в твердых растворах $\mathrm{Cu}_{1-x}\left(\operatorname{In}_{0.7} \mathrm{Ga}_{0.3}\right) \mathrm{Se}_{2}$ в подрешетке меди имеются вакансии $V_{\mathrm{Cu}}$. Для сохранения электронейтральности кристалла на $x$ вакансий в подрешетке меди $x$ атомы меди приобретают степень окисления +2 .

\section{3. Результаты и обсуждение}

\section{1. Кинетика гибели фотогенерированных носителей тока}

При включении света отраженная мощность сначала резко возрастала - „фотоотклик“, а затем постепенно возвращалась к исходному состоянию. Спады фотоотклика к исходному состоянию для образцов $\mathrm{Cu}_{1-x}\left(\mathrm{In}_{0.7} \mathrm{Ga}_{0.3}\right) \mathrm{Se}_{2}$ различных составов (разных $x$ ) представляли собой сложную функцию: либо сумму двух экспонент, либо сумму экспоненты и гиперболы. В таблице приведены сводные данные по характеристическим временам спадов фотоотклика в 2 раза $\left(\tau_{1 / 2}\right)$.
Можно видеть, что при уменьшении содержания меди характеристические времена $\tau_{1 / 2}$ уменьшаются.

Зависимость амплитуты фотоотклика от интенсивности света $\Delta P_{\max }\left(I_{0}\right)$ была линейной при $x=0$, но становилась нелинейной при увеличении значения $x$.

На рис. 1 показаны зависимости амплитуды отклика от частоты СВЧ-генератора для некоторых моментов времени, прошедшего после начала действия лазерного импульса в образцах $\mathrm{Cu}\left(\mathrm{In}_{0.7} \mathrm{Ga}_{0.3}\right) \mathrm{Se}_{2}$ и $\mathrm{Cu}_{0.6}\left(\mathrm{In}_{0.7} \mathrm{Ga}_{0.3}\right) \mathrm{Se}_{2}$. Из рисунка видно, что в начале спада фотоотклика график частотной зависимости пересекает ось частот дважды, причем сама кривая имеет несимметричный относительно резонансной частоты $f_{0}$ вид. С течением времени, прошедшего после импульса возбуждения, форма частотной зависимости меняется, при этом изменяется расположение точек $f_{1}^{0}$ и $f_{2}^{0}$ на оси частот, соответствующих значениям $\Delta P=0$ слева и справа от значения $f_{0}$ (пунктирная линия на графиках): кривая становится более симметричной. Это свидетельствует о том, что вклад сдвига резонансной частоты в фотоотклик отрицательный, заметный в начальный момент времени и постепенно снижающийся и становящийся пренебрежимо малым в сравнении с вкладом в фотоотклик изменения добротности резонатора $[14,15]$.

На рис. 2 в логарифмических координатах и на рис. 3 в двойных логарифмических координатах представлены

Времена полуспада фотоотклика твердых растворов $\mathrm{Cu}_{1-x}\left(\operatorname{In}_{0.7} \mathrm{Ga}_{0.3}\right) \mathrm{Se}_{2}$

\begin{tabular}{c|c}
\hline Образец & $\tau_{1 / 2}, \mathrm{Hc}$ \\
\hline $\mathrm{Cu}\left(\mathrm{In}_{0.7} \mathrm{Ga}_{0.3}\right) \mathrm{Se}_{2}$ & $140 \pm 30$ \\
$\mathrm{Cu}_{0.9}\left(\mathrm{In}_{0.7} \mathrm{Ga}_{0.3}\right) \mathrm{Se}_{2}$ & $100 \pm 15$ \\
$\mathrm{Cu}_{0.8}\left(\mathrm{In}_{0.7} \mathrm{Ga}_{0.3}\right) \mathrm{Se}_{2}$ & $75 \pm 25$ \\
$\mathrm{Cu}_{0.7}\left(\mathrm{In}_{0.7} \mathrm{Ga}_{0.3}\right) \mathrm{Se}_{2}$ & $<50$
\end{tabular}



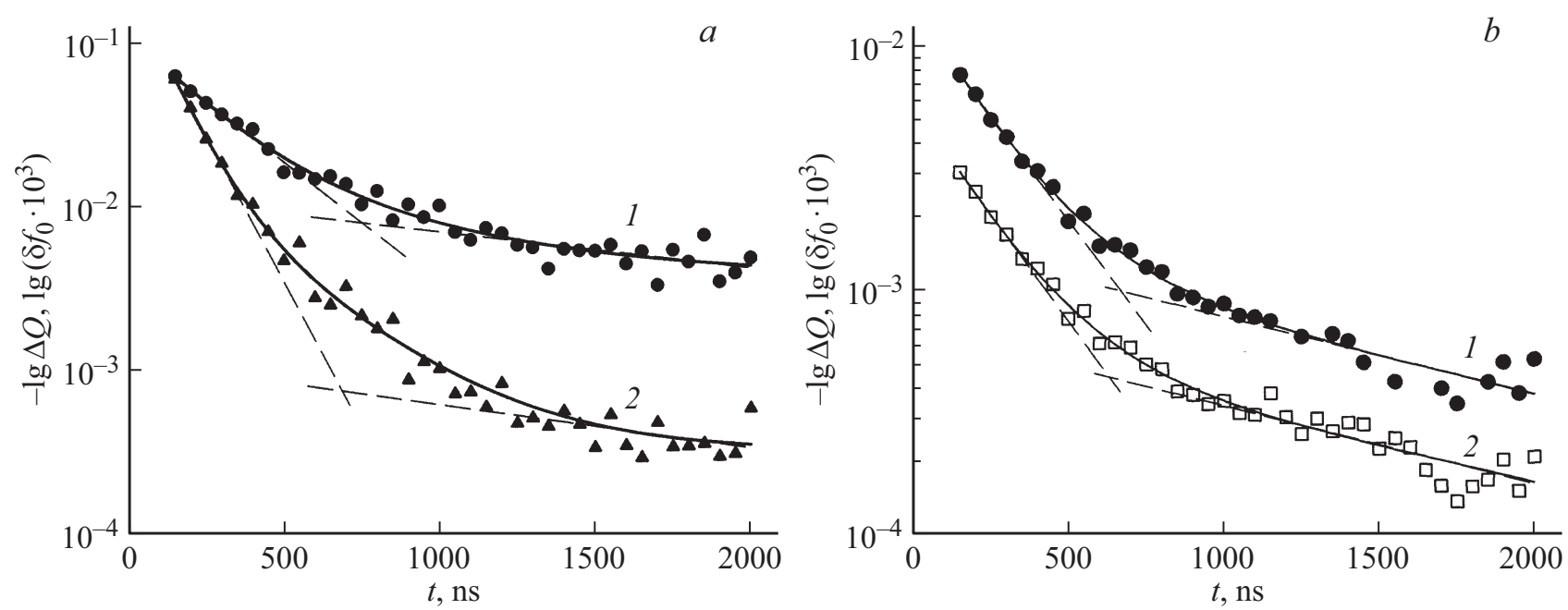

Рис. 2. Зависимость изменения добротности $\Delta Q(1)$ и сдвига резонансной частоты $\delta f_{0}(2)$ от времени для твердых растворов $\mathrm{Cu}\left(\mathrm{In}_{0.7} \mathrm{Ga}_{0.3}\right) \mathrm{Se}_{2}(a)$ и $\mathrm{Cu}_{0.6} \mathrm{In}_{0.7} \mathrm{Ga}_{0.3} \mathrm{Se}_{2}(b)$ в логарифмических координатах.
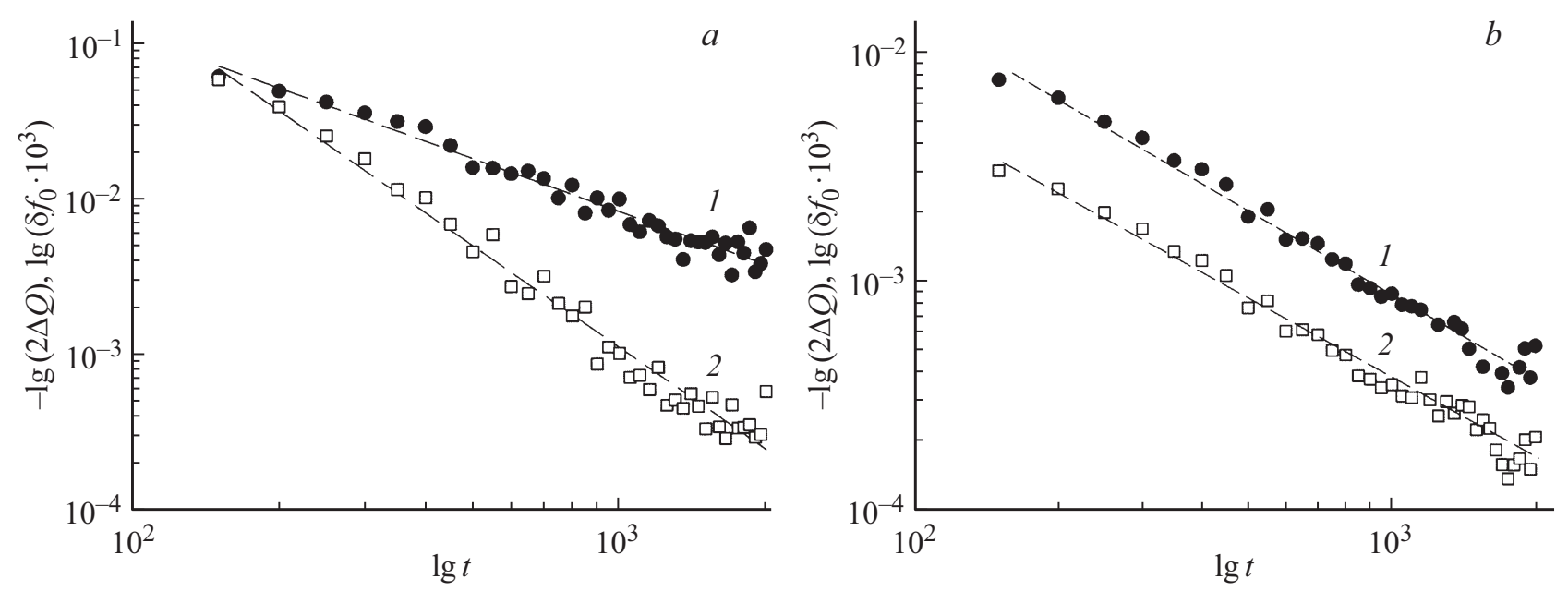

Рис. 3. Зависимость изменения добротности $\Delta Q(1)$ и сдвига резонансной частоты $\delta f_{0}(2)$ от времени для твердых растворов $\mathrm{Cu}\left(\operatorname{In}_{0.7} \mathrm{Ga}_{0.3}\right) \mathrm{Se}_{2}(a)$ и $\mathrm{Cu}_{0.6} \mathrm{In}_{0.7} \mathrm{Ga}_{0.3} \mathrm{Se}_{2}(b)$ в двойных логарифмических координатах.

зависимости изменения добротности $(\Delta Q)^{-1}$ и сдвига резонансной частоты $\delta f_{0}$ для образцов $\mathrm{Cu}\left(\mathrm{In}_{0.7} \mathrm{Ga}_{0.3}\right) \mathrm{Se}_{2}$ и $\mathrm{Cu}_{0.6} \mathrm{In}_{0.7} \mathrm{Ga}_{0.3} \mathrm{Se}_{2}$, полученные в результате такого анализа. Можно видеть, что двойные логарифмические координаты лучше подходят для спрямления экспериментальных зависимостей, чем логарифмические.

Из рис. 3, $a$ видно, что скорости спадов $(\Delta Q)^{-1}$ и $\delta f_{0}$ вплоть до момента времени $\Delta \tau \sim 800$ нс в образце $\mathrm{Cu}\left(\mathrm{In}_{0.7} \mathrm{Ga}_{0.3}\right) \mathrm{Se}_{2}$ различаются приблизительно в 2 раза: спад $(\Delta Q)^{-1}(t)$ описывается гиперболой вида $t^{-1}$, а $\delta f_{0}(t)$ - вида $t^{-2}$. В то же время в образце $\mathrm{Cu}_{0.6} \mathrm{In}_{0.7} \mathrm{Ga}_{0.3} \mathrm{Se}_{2}$ спады были одинаковые гиперболические.

Так как дрейфовая подвижность электронов в CIGS заметно выше подвижности дырок, фотоотклик естественно относить в основном к участию в микроволновой фотопроводимости электронов. При этом, согласно данным работы [15], различие скоростей спадов $(\Delta Q)^{-1}(t)$ и $\delta f_{0}(t)$ может быть связано с отсутствием равновесия по электронам между ловушками и зоной проводимости длительное время после окончания импульса лазера. Однако при малом содержании меди $(x=0.4)$ скорости спадов $(\Delta Q)^{-1}(t)$ и $\delta f_{0}(t)$ быстро выравниваются, что указывает на установление равновесия по электронам между ловушками и зоной проводимости уже на временах $<50$ нс. Естественно считать характеристическое время установления равновесия „временем жизни“ свободного носителя тока

\section{2. Спектры люминесценции}

В спектре катодолюминесценции (КЛ $)(T=298 \mathrm{~K})$ образца $\mathrm{Cu}\left(\mathrm{In}_{0.7} \mathrm{Ga}_{0.3}\right) \mathrm{Se}_{2}$ (рис. 4, спектр $I^{\prime}$ ) имеется полоса с максимумом 1.17 эВ; это значение энергии отвечает ширине запрещенной зоны $E_{g}$ : переходу валентная зона - зона проводимости, что соответствует лите- 


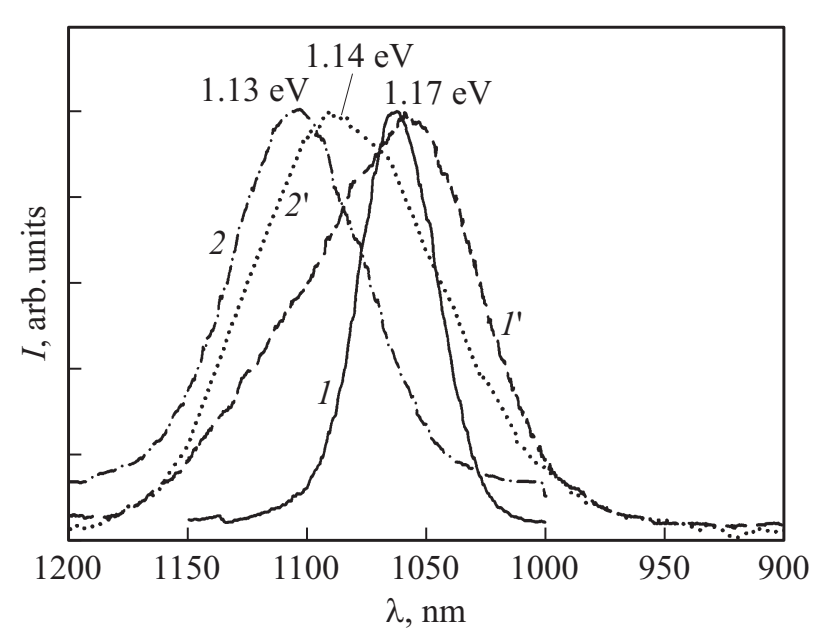

Рис. 4. Нормированные спектры КЛ твердых растворов $\mathrm{Cu}_{1-x}\left(\operatorname{In}_{0.7} \mathrm{Ga}_{0.3}\right) \mathrm{Se}_{2}: 1,1^{\prime}-x=0,2,2^{\prime}-x=0.3$. $1,2-78 \mathrm{~K} ; 1^{\prime}, 2^{\prime}-298 \mathrm{~K}$.

ратурным данным [17]. Также в спектрах КЛ $(T=298 \mathrm{~K})$ твердых растворов $\mathrm{Cu}_{1-x}\left(\mathrm{In}_{0.7} \mathrm{Ga}_{0.3}\right) \mathrm{Se}_{2}$ на рис. 4 наблюдается широкая полоса с максимумом 1.14 эВ при $x=0.3$ (спектр $2^{\prime}$ ). Эти полосы также обусловлены межзонными переходами. Отметим, что при увеличении $x$ до 0.3 происходит уменьшение интенсивности люминесценции.

В спектре КЛ $(T=78 \mathrm{~K}) \mathrm{Cu}_{1-x}\left(\operatorname{In}_{0.7} \mathrm{Ga}_{0.3}\right) \mathrm{Se}_{2}(x=0)$ также проявляется полоса с максимумом 1.17 эВ (рис. 4 , спектр 1). Экситонные линии, которые бы однозначно свидетельствовали о точном значении ширины запрещенной зоны $E_{g}$, не обнаружены. Значение $E_{g}$ для образца с $x=0$, определяемое из спектров оптического поглощения, составляет 1.20 эВ. Полоса 1.17 эВ соответствует образованию в запрещенной зоне акцепторного уровня, обусловленного вакансиями меди $V_{\mathrm{Cu}}[18,19]$. В спектре КЛ $(T=78 \mathrm{~K})$ образца твердых растворов $\mathrm{Cu}_{1-x}\left(\operatorname{In}_{0.7} \mathrm{Ga}_{0.3}\right) \mathrm{Se}_{2} \mathrm{c} x=0.3$ наблюдается широкая полоса с максимумом 1.13 эВ (рис. 4, спектр 2). Безусловно, полоса 1.13 эВ связана с наличием меди в степени окисления +2. Смещение полосы 1.17 до 1.13 эВ (рис. 4 , спектры 1,2) обусловлено, по всей вероятности, тем, что происходит связывание вакансий меди в ассоциаты дефектов $\mathrm{Cu}^{+2} V_{\mathrm{Cu}}$.

\section{4. Обсуждение}

Как предположено в работе [10], медь в степени окисления +2 находится в подрешетке меди в позициях, которые при $x=0$ занимала медь в степени окисления +1 , концентрация вакансий $V_{\mathrm{Cu}}$ в подрешетке меди равна концентрации $\mathrm{Cu}^{+2}$, эти концентрации велики, и преобладающим типом дефектов будут ассоциаты $\mathrm{Cu}^{+2} V_{\mathrm{Cu}}$. Безусловно, при $78 \mathrm{~K}$ кроме указанных ассоциатов велики концентрации и одиночных дефектов $V_{\mathrm{Cu}}$ и $\mathrm{Cu}^{+2}$. Кроме того, следует учитывать, что указанные ассоциаты дефектов при повышении температуры от 78 до $298 \mathrm{~K}$ полностью диссоциируют.

Заметим, что положение максимума полосы при всех значениях $x$ в области $0.1-0.3$ остается одним и тем же $(1.13$ эВ), хотя состав изменяется в широких пределах. По-видимому, строение твердых растворов $\mathrm{Cu}_{1-x}\left(\mathrm{In}_{0.7} \mathrm{Ga}_{0.3}\right) \mathrm{Se}_{2}$ одинаково для всей области составов, во всех случаях имеются вышеуказанные ассоциаты дефектов.

Естественно принять, что с уменьшением содержания меди в $\mathrm{Cu}_{1-x}\left(\mathrm{In}_{0.7} \mathrm{Ga}_{0.3}\right) \mathrm{Se}_{2}$ увеличивается концентрация вакансий $V_{\mathrm{Cu}}$ - электронных ловушек, что должно приводить к уменьшению времени жизни фотогенерированных носителей тока и эффективной конкуренции процесса захвата с процессом рекомбинации и, следовательно, к линейной зависимости фотоотклика от интенсивности света. Для объяснения нелинейной зависимости при высоких уровнях освещенности обычно привлекают процесс гибели носителей тока во время действия импульса света. Наши результаты не согласуются с таким объяснением. Поэтому для объяснения этих особенностей в работах $[10,11]$ нами были учтены обнаруженные парамагнитные свойства CIGS [9]. При высоких уровнях освещенности размер скин-слоя мог оказаться сравнимым с характеристической длиной поглощения света $\sim 10^{-5}$ см. В этом случае участие носителей тока в потерях энергии в резонаторе при максимальных интенсивностях может стать менее эффективным, что приведет к кажущейся нелинейности в зависимостях $\Delta P_{\max }\left(I_{0}\right)$. Но необходимо учитывать, что в образцах с малой концентрацией вакансий меди, вероятно, уже во время импульса лазера происходит быстрое заполнение ловушек, что приводит к замедлению процесса рекомбинации. С этим предположением согласуется также обнаруженный факт, что от содержания меди зависела форма зависимости амплитуды фотоотклика $\Delta P_{\max }\left(I_{0}\right)$ от интенсивности света: в твердых растворах с бо́льшим содержанием меди зависимость была линейной, тогда как в образцах с меньшим содержанием меди наблюдалась нелинейная зависимость.

Для объяснения наблюдаемых особенностей кинетики микроволновой фотопроводимости можно представить следующие процессы (не показаны стадии генерации и рекомбинации фотогенерированных электронов и дырок) [20]:

$$
\begin{aligned}
& e^{-}+A \stackrel{1 / \tau_{\mathrm{tr}}^{e}}{\longrightarrow} A^{-}, \\
& p^{+}+B \stackrel{1 / \tau_{\mathrm{tr}}^{p}}{\longrightarrow} B^{+}, \\
& p^{+}+A^{-} \stackrel{1 / \tau_{\mathrm{rec}}}{\longrightarrow} A, \\
& A^{-} \stackrel{1 / \tau^{e}}{\longrightarrow} e^{-}+A, \\
& B^{+} \stackrel{1 / \tau^{p}}{\longrightarrow} p^{+}+B,
\end{aligned}
$$

где $\tau_{\mathrm{tr}}^{e}$ и $\tau_{\mathrm{tr}}^{p}-$ времена жизни до захвата в ловушки электронов и дырок соответственно, $\tau_{\text {rec }}-$ время жизни 


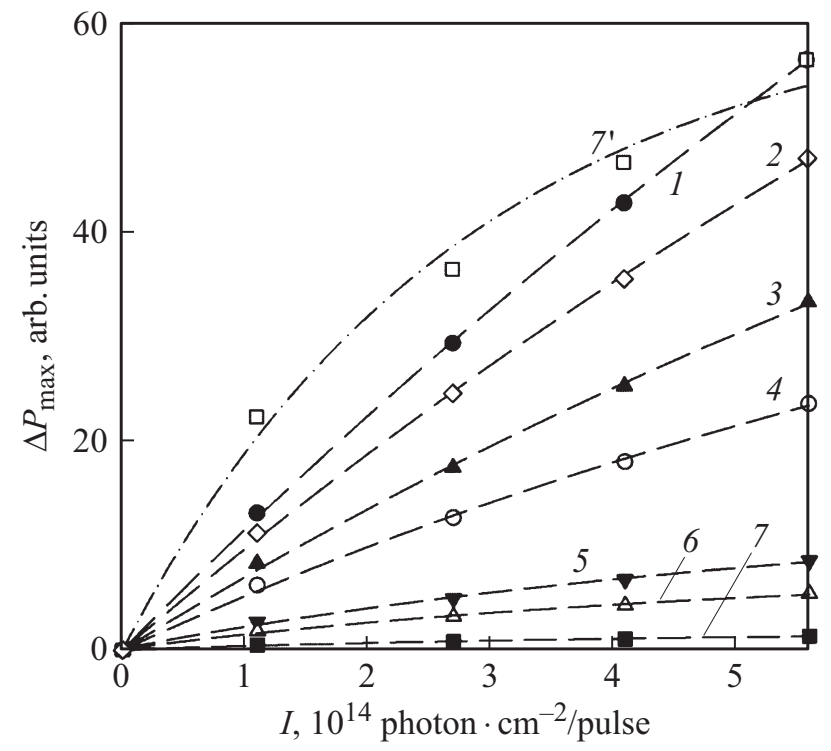

Рис. 5. Рассчитанные зависимости амплитуды фотоотклика от количества квантов света при разных концентрациях электронных ловушек: $1-10^{18}, 2-2 \cdot 10^{18}, 3-5 \cdot 10^{18} ; 4-10^{19}$, $5-5 \cdot 10^{19}, 6-10^{20}, 7$ и $7^{\prime}-10^{21} \mathrm{~cm}^{-3}$. Кривая $7^{\prime}-$ приведенная по амплитуде зависимость к концентрации электронных ловушек $10^{18} \mathrm{~cm}^{-3}$.

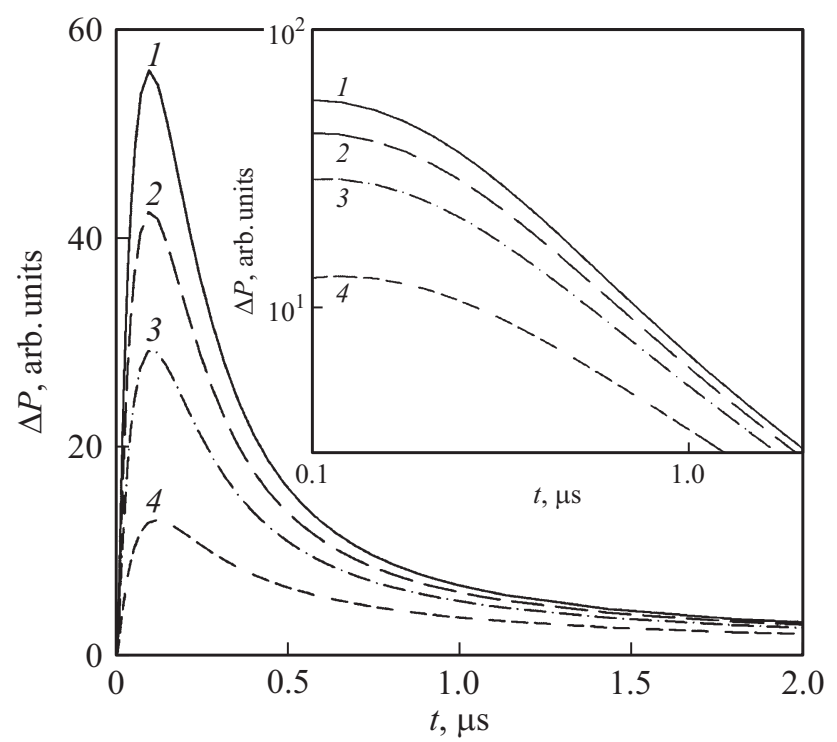

Рис. 6. Рассчитанные спады фотоотклика при разных интенсивностях света: $1-5.6 \cdot 10^{14}, 2-4.1 \cdot 10^{14}, 3-2.7 \cdot 10^{14}$, $4-1 \cdot 10^{14}$ фотон $\cdot \mathrm{cm}^{-2}$ за импульс. На вставке показаны спады в двойных логарифмических координатах.

до рекомбинации локализованных электронов и свободных дырок (рекомбинация через локальные центры), $\tau^{e}$ и $\tau^{p}$ - времена термического выхода захваченных носителей тока из электроных $(A)$ и дырочных $(B)$ ловушек соответственно. В демонстрационном расчете принято $\tau_{\text {tr }}^{e}=200$ нс (для концентрации электронных ловушек $10^{18} \mathrm{~cm}^{-3}$ ), $\tau_{\mathrm{tr}}^{p}=0.1 \mathrm{Hс}, \tau^{e}=0.1$ нс и $\tau^{p}=0.1 \mathrm{нс}$ (глу- бины ловушек $E=0.24$ эВ). При выбранных параметрах медленной стадией является захват электрона.

На рис. 5 показаны рассчитанные зависимости амплитуды фотоотклика от количества квантов света при разных концентрациях электронных ловушек. В расчете учитывалось неоднородное поглощение света, конечная ширина импульса лазера и конечное временно́е разрешение установки (рис. 6). Для удобства сравнения зависимостей штрихпунктирной линией (с незаполненными квадратами) на рисунке показана зависимость при большой концентрации электронных ловушек, приведенная по амплитуде к зависимости при малых концентрациях электронных ловушек. Из рис. 5 видно, что с ростом концентрации электронных ловушек зависимость амплитуды фотоотклика от интенсивности падающего света становится нелинейной, что отвечает эксперименту.

\section{5. Заключение}

Таким образом, при исследованиии микроволновой фотопроводимости и катодолюминесценции установлено, что с уменьшением содержания меди в твердых растворах со структурой халькопирита $\mathrm{Cu}_{1-x}\left(\mathrm{In}_{0.7} \mathrm{Ga}_{0.3}\right) \mathrm{Se}_{2}$, $0<x \leq 0.4$ (т.е. с увеличением $x$ ) растет концентрация вакансий $V_{\mathrm{Cu}}$, которые являются электронными ловушками, что приводит к уменьшению времени жизни фотогенерированных носителей тока и, следовательно, к уменьшению диффузионной длины пробега электрона. Особенности кинетики процесса гибели фотогенерированных носителей тока, проявляющиеся при изменениях в широком диапазоне состава образцов и интенсивности света, нашли отражение в результатах численного расчета при учете неоднородного поглощения света, конечной ширины импульса возбуждающего света и временно́го разрешения экспериментальной установки. При повышении плотности лазерного излучения до уровня $\sim 5 \cdot 10^{14}$ фотон $/ \mathrm{cm}^{2}$ за импульс в характере фотоотклика наряду с ранее обнаруженным скин-эффектом проявляется эффект заполнения ловушек, создаваемых вакансиями $V_{\mathrm{Cu}}$ и ассоциатами дефектов $\mathrm{Cu}^{+2} \cdot V_{\mathrm{Cu}}$. Удовлетворительное согласие расчета кинетики фотоотклика с экспериментом достигнуто при времени жиэни электрона до захвата ловушками $\tau_{\mathrm{tr}}=200$ нс (для концентрации электронных ловушек $10^{18} \mathrm{~cm}^{-3}$ ). Наблюдаемая гиперболическая форма спадов фотоотклика после окончания лазерного импульса при линейной зависимости $\Delta P_{\max }\left(I_{0}\right)$ в образцах с $x=0$, вероятно, свидетельствует об определяющем вкладе поверхностной рекомбинации в процессе гибели носителей тока в условиях нашего эксперимента.

Работа выполнена с использованием УНУ: „Установка для измерения времен жизни фотогенерированных носителей тока методом микроволновой фотопроводимости в диапазоне частот 9 ГГц“. 
Работа выполнена при финансовой поддержке РФФИ (проект № 16-08-01234) и государственного задания № 01201361850 .

\section{Список литературы}

[1] А. Фаренбрух, Р. Бъюб. Солнечные элементы. Теория $и$ эксперимент (М., Энергоатомиздат, 1987) гл. 1, с. 11.

[2] M. Burgelman, J. Marlein. Proc. References the 23rd Eur. Photovoltaic Solar Energy Conf. (Valencia, Spain, 2008) p. 2151.

[3] P. Jackson, D. Hariskos, E. Lotter, S. Paetel, R. Wuerz et al. Progr. Photovolt. Res. Appl., 19, 894 (2010).

[4] E.R. Baek, V. Astini, A. Tirta, B. Kim. Curr. Appl. Phys., 11 (1), S76 (2011).

[5] S. Spiering, S. Paetel, F. Kessle, M. Igalson, H.A. Maksoud. Thin Sol. Films, 582, 328 (2015).

[6] M. Turcu, O. Pakma, U. Rau. Appl. Phys. Lett., 80 (14), 2598 (2002).

[7] V. Deprédurand, D. Tanaka, Y. Aida, M. Carlberg, N. Fèvre et al. J. Appl. Phys., 115, 044503 (2014).

[8] Hung-Ing Chen, Jen-Cheng Wang, Chia-Hui Fang, YuTing Liang, Tung-Po Hsieh et al. Appl. Mech. Mater., 110-116, 1187 (2012).

[9] I.N. Odin, M.V. Chukichev, M.V. Gapanovich, A.V. Vasil'ev, G.F. Novikov. Mendeleev Commun., 28 (3), 248 (2018).

[10] М.В. Гапанович, И.Н. Один, Е.В. Рабенок, П.С. Оришина, Г.Ф. Новиков. Неорг. матер., (2018), в печати.

[11] П.С. Оришина, Е.В. Рабенок, Г.Ф. Новиков. Науч. альманах, 41 (3-2), 178 (2018).

[12] I.L. Repins, W.K. Metzger, C.L. Perkins, J.V. Li, M.A. Contreras. Proc. 34th IEEE Photovoltaic Specialists Conf. (PVSC) (Philadelphia, Pennsylvania, USA, 2009) p. 000978.

[13] T. Sakurai, K. Taguchi, M.M. Islam, S. Ishizuka, A. Yamada et al. Jpn. J. Appl. Phys., 50, 05FC01 (2011).

[14] G.F. Novikov, A.A. Marinin, E.V. Rabenok. Instrum. Exp. Techn., 53 (2), 233 (2010).

[15] G.F. Novikov. J. Renewable and Sustainable Energy, 7, 011204 (2015).

[16] М.В. Гапанович, И.Н. Один, М.В. Чукичев, В.Ф. Козловский, Г.Ф. Новиков. Неорг. матер., 52 (1), 53 (2016).

[17] M. Venkatachalam, M.D. Kannan. S. Jayakumar, R. Balasundaraprabhu, A.K. Nandakumar et al. Solar Energy Mater. Solar Cells, 92, 571 (2008).

[18] Myoung Guk Park, Sejin Ahn, Jae Ho Yun, Jihye Gwak, Ara Cho et al. J. Alloys Comp., 513, 68 (2012).

[19] M. Theelen, C. Foster, H. Steijvers, N. Barreau, Z. Vroon et al. Solar Energy Mater. Solar Cells, 141, 49 (2015).

[20] G.F. Novikov. Sci. Appl. Photogr., 39 (6), 513 (1998).

Редактор А.Н. Смирнов

\section{Influence of copper content on the kinetics of microwave photoconductivity of CIGS solid solutions}

\author{
G.F. Novikov ${ }^{\mathbf{1 , 2}}$, E.V. Rabenok ${ }^{1}$, P.S. Orishina ${ }^{\mathbf{1 , 2}}$, \\ M.V. Gapanovich ${ }^{1}$, I.N. Odin ${ }^{2}$ \\ ${ }^{1}$ Institute of Problems of Chemical Physics, \\ Russian Academy of Sciences, \\ 142432 Chernogolovka, Russia \\ 2 Lomonosov Moscow State University, \\ 119991 Moscow, Russia
}

\begin{abstract}
The kinetics of the photoresponse of microwave photoconductivity ( $9 \mathrm{GHz}, \mathrm{TE}_{101}$-type cavity resonator) was studied under excitation by laser pulses of light (wavelength $337 \mathrm{~nm}$, duration $8 \mathrm{~ns}$ ) in copper-deficient solid solutions with chalcopyrite structure $\mathrm{Cu}_{1-x}\left(\mathrm{In}_{0.7} \mathrm{Ga}_{0.3}\right) \mathrm{Se}_{2}, 0<x \leq 0.4$ (CIGS) in a wide range of light intensities. When the density of laser radiation is increased to a level of $\sim 5 \cdot 10^{14}$ photon $/ \mathrm{cm}^{2}$ per pulse in the nature of the photoresponse, along with the previously detected skin effect, the effect of filling traps created by vacancies $V_{\mathrm{Cu}}$ and associates of defects $\mathrm{Cu}^{+2} \cdot V_{\mathrm{Cu}}$, whose concentration increases with decreasing $x$ in the formula for CIGS.
\end{abstract}

